University of Nebraska - Lincoln

DigitalCommons@University of Nebraska - Lincoln

\title{
Non-linear responses of glaciated prairie wetlands to climate warming
}

W. Carter Johnson

South Dakota State University, Brookings, carter.johnson@sdstate.edu

Brett Werner

Centre College, Danville Kentucky

Glenn R. Guntenspergen

Patuxent Wildlife Research Center, U.S. Geological Survey

Follow this and additional works at: https://digitalcommons.unl.edu/usgsstaffpub

Part of the Geology Commons, Oceanography and Atmospheric Sciences and Meteorology Commons, Other Earth Sciences Commons, and the Other Environmental Sciences Commons

Johnson, W. Carter; Werner, Brett; and Guntenspergen, Glenn R., "Non-linear responses of glaciated prairie wetlands to climate warming" (2016). USGS Staff-- Published Research. 1147.

https://digitalcommons.unl.edu/usgsstaffpub/1147

This Article is brought to you for free and open access by the US Geological Survey at DigitalCommons@University of Nebraska - Lincoln. It has been accepted for inclusion in USGS Staff -- Published Research by an authorized administrator of DigitalCommons@University of Nebraska - Lincoln. 


\title{
Non-linear responses of glaciated prairie wetlands to climate warming
}

\author{
W. Carter Johnson ${ }^{1} \cdot$ Brett Werner $^{2}$ • \\ Glenn R. Guntenspergen ${ }^{3}$
}

Received: 5 January 2015 / Accepted: 10 October 2015 /Published online: 22 October 2015

(C) Springer Science+Business Media Dordrecht 2015

\begin{abstract}
The response of ecosystems to climate warming is likely to include threshold events when small changes in key environmental drivers produce large changes in an ecosystem. Wetlands of the Prairie Pothole Region (PPR) are especially sensitive to climate variability, yet the possibility that functional changes may occur more rapidly with warming than expected has not been examined or modeled. The productivity and biodiversity of these wetlands are strongly controlled by the speed and completeness of a vegetation cover cycle driven by the wet and dry extremes of climate. Two thresholds involving duration and depth of standing water must be exceeded every few decades or so to complete the cycle and to produce highly functional wetlands. Model experiments at 19 weather stations employing incremental warming scenarios determined that wetland function across most of the PPR would be diminished beyond a climate warming of about $1.5-2.0{ }^{\circ} \mathrm{C}$, a critical temperature threshold range identified in other climate change studies.
\end{abstract}

\section{Introduction}

Threshold and other non-linear ecosystem responses have been the subject of research in ecological theory for decades, and intellectual progress has been made in elucidating their role in ecosystem behavior and dynamics (e.g., Holling 1973, May 1977, Gunderson 2000, Fagre et al. 2009). A threshold has been defined as a point of abrupt change in ecosystem

Electronic supplementary material The online version of this article (doi:10.1007/s10584-015-1534-8) contains supplementary material, which is available to authorized users.

W. Carter Johnson

carter.johnson@sdstate.edu

1 Department of Natural Resource Management, South Dakota State University, Brookings, SD 57007, USA

2 Environmental Studies, Centre College, Danville, KY 40422, USA

3 Patuxent Wildlife Research Center, U. S. Geological Survey, Laurel, MD 20708, USA 
characteristics or processes (e.g., productivity, structure, composition) or where small changes in key environmental drivers produce large changes in an ecosystem (Groffman et al. 2006). Commonly cited examples of threshold effects are: model generated level of fragmentation beyond which "percolation" or mobility of organisms is sharply restricted across landscapes (Gardner et al. 1987); abrupt shift in water clarity when the balance among key disturbances (hurricanes, grazing, nutrients, salinity) changes (Gunderson and Holling 2002); specific hydrogeomorphic thresholds needed to initiate river channel meandering, point bar formation, and recruitment of flood dependent riparian species such as Populus (Johnson 1998, Scott et al. 1996).

Interest in thresholds has surged recently associated with the study of climate change (e.g., Fagre et al. 2009) and the need for management responses (Guntenspergen and Gross 2014). Concerns are that if key drivers of natural ecosystem function are related non-linearly to the climate, changes might occur more rapidly than expected based on traditional analyses (proportional; Burkett et al. 2005) or that unforeseen effects in the current climate might occur in the future climate. One perceived benefit of research in this area is that if temperature thresholds can be forecasted, mitigation potential to avoid ecosystem impairment in the future is improved.

The Prairie Pothole Region (PPR) is a $750,000 \mathrm{~km}^{2}$ area in central North America (Fig. 1) studded with 5-8 million wetland basins of recent glacial origin. These wetlands are best known as prime nesting and migratory habitat for water birds, but they provide other important ecosystem services including flood retention, groundwater recharge, water purification, recreation, agriculture, and regional biodiversity (van der Valk 1989). Loss of wetland and adjacent grassland habitat has accelerated in recent years because of drainage and land conversion to agriculture driven by record grain prices (Wright and Wimberly 2013).

A common thread running through the study of wetlands in the PPR is the controlling influence of a climate-driven water regime. Hydrology is the most important factor controlling key wetland processes and services (Winter and Woo 1990). Winter (2000) predicted that the surface area of seasonal and semi-permanent wetlands in a warmer climate would be reduced by increases in evapotranspiration and reduced summer soil moisture. Higher summer evapotranspiration would put increasing demands on groundwater resulting in earlier drying of wetlands.

The variable climate of the Great Plains (Millett et al. 2009) produces a strong oscillation in water regime and biodiversity (Winter and Rosenberry 1998, Johnson et al. 2004, van der Valk 2005). These dynamics were captured in a descriptive model (Supplemental Figure 1) best applied to semi-permanent wetlands by van der Valk and Davis (1978) and now considered a foundational concept in wetland ecology (e.g., Mitsch and Gosselink 2007; Batzer and Sharitz 2006).

The drought and deluge frequencies characteristic of a given climate determine the speed of the nutrient and vegetation cycles in prairie wetlands (Weller and Spatcher 1965, Murkin et al. 2000). Prolonged high water produces a "lake" wetland with little emergent plant cover and few nutrients in detritus, while persistent low water produces a "dry" stage with heavy emergent cover and high nutrient sequestering in plant material. The occurrence of both extremes during a weather cycle causes plant population turnover (maintaining biological diversity) and nutrient mobilization and maintains high primary and secondary productivity.

The lake and dry marsh stages each can be conceived as opposing poles in the cycle that may persist for a decade or more, while the degenerating and regenerating stages are passed through more quickly on the way to either pole. 

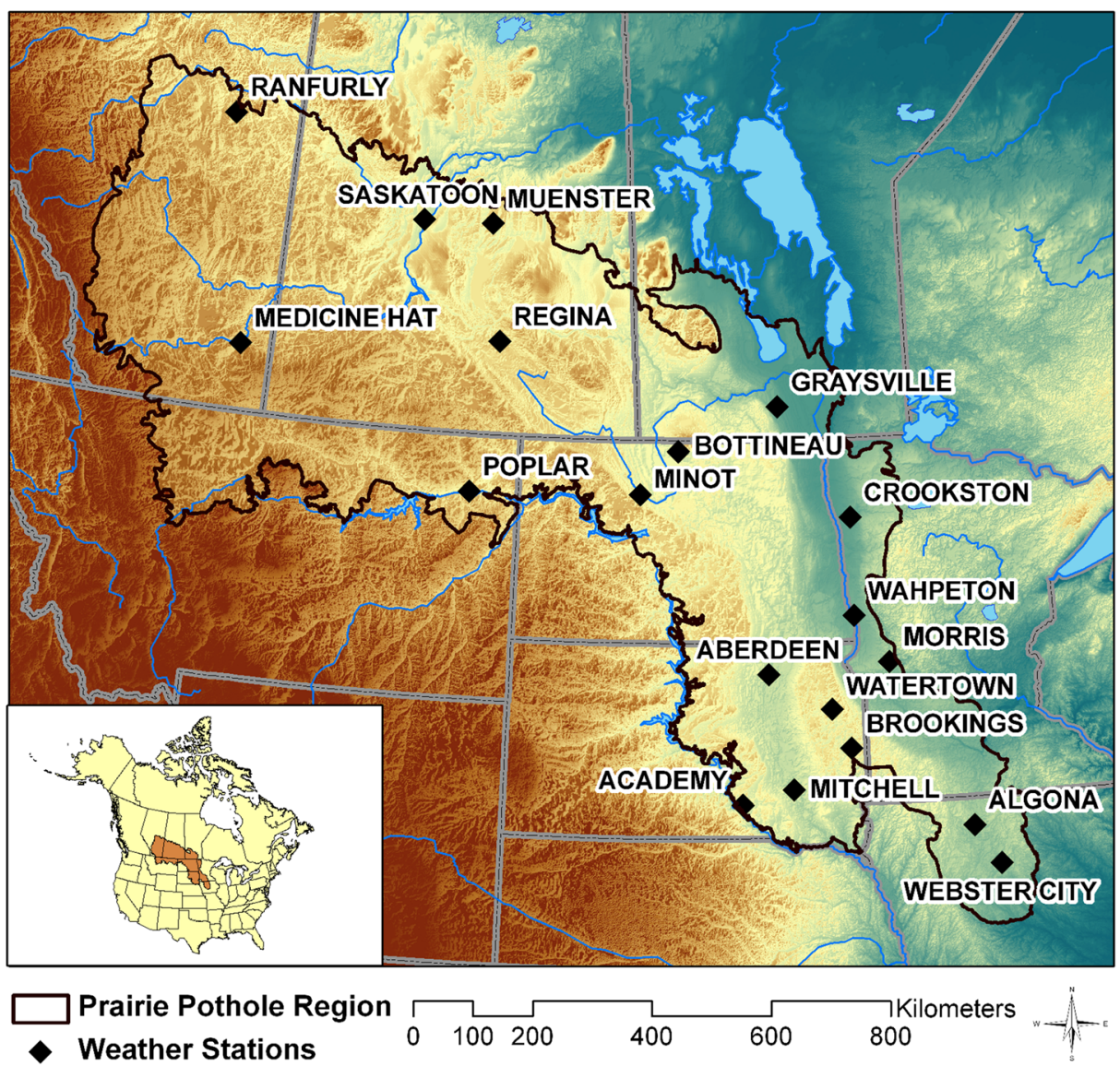

Fig. 1 Location of the Prairie Pothole Region within North America, and the names and locations of long-term weather stations used in this analysis

Regenerating and degenerating stages are often combined into a hemi-marsh stage with approximately equal proportions of emergent cover and open water, considered to be the most productive stage of the cycle (Weller and Spatcher 1965).

The speed and completeness (all stages reached over time) of the wetland cover cycle are not only sensitive to climate variability, but the responses are non-linear (Johnson et al. 2005). Two key thresholds must be exceeded to complete one cycle (Supplemental Table 1). These are: (1) switch from the dry marsh stage to the regenerating stage after re-flooding (0.4-1.0 m water depth for 1.5 consecutive growing seasons). This kills intolerant plant species but leaves the emergent vegetation. Prolonged high water removes emergent vegetation and shifts the wetland into the degenerating stage and eventually into the lake marsh stage; (2) a second water depth threshold of $<0.1 \mathrm{~m}$ for several early growing season months works in the opposite direction and marks a shift from the lake marsh stage to the dry marsh stage. Switching here allows emergent and mud flat plant species to germinate from the seed bank (Poiani et al. 1995). Unless these two key thresholds are met by the climate, wetlands often become "stuck" for decades in the less productive lake marsh or the "choked" dry marsh stages. The lake marsh stage, when prolonged, was described by Weller and Fredrickson (1974) as a "biological desert." 
The long-term (i.e., multi-decadal) patterns of the cover cycle vary widely across the PPR because of the intersection of a strong west-east precipitation gradient, caused by the rain shadow of the Rocky Mountains, and a moderate latitudinal temperature gradient (Supplemental Figure 2). This intersection produces many sub-regional climates and ecoregions (Millett et al. 2009), despite the relatively small size of the PPR. During the 20th century, the speed of the cover cycle was fastest in mid-sections of the PPR; wetlands in the drier western climate stayed in the dry marsh longer and in the wetter eastern climate wetlands stayed in the lake marsh stage longer (Johnson et al. 2005).

Wetland ecosystems are especially sensitive to climate variability (Larson 1995, Clair 1998, Johnson et al. 2005, van der Valk 2012), and therefore, are more likely than terrestrial ecosystems to be affected by a change in climate. As such, there is a need to identify, study, and evaluate key wetland ecological processes driven by climate that could reach or surpass threshold levels within scenarios of climate change.

Cover cycle thresholds are well-known from field research; what is not known is how future climates may change the frequencies at which these thresholds are reached, both at specific sites and more broadly across the strong climate gradients and high climate variability in the PPR. Our objectives to address this need were to: (1) simulate, through modeling, changes in climate favorability under incremental increases in air temperature $\left(0.20^{\circ} \mathrm{C}\right)$ over a range of $0-5{ }^{\circ} \mathrm{C}$ at each of $19 \mathrm{PPR}$ weather stations; (2) integrate results across weather stations to characterize broad PPR patterns of projected changes in climate favorability; and (3) determine if the modeling identifies a threshold temperature across the PPR, that if crossed in the future, would render the region's wetlands chronically less functional than under the 20th century climates.

Our analytical approach was not to predict the climate and status of prairie wetlands in the future, but rather to examine the functional behavior of the prairie wetland ecosystem under a range of probabilistic, but precisely unknowable, future temperatures. An additional product of this approach was quantification of the sensitivity of prairie wetlands to incremental changes in temperature.

\section{Methods}

\subsection{Model}

All simulations in this paper were produced using WETLANDSCAPE (WLS), a climatedriven, process-based, deterministic model of prairie wetland complexes (Johnson et al. 2010). WLS simulates wetland surface water, groundwater, and vegetation dynamics of the wetland complex, including overflows between basins.

WLS was parameterized and tested using long-term (1993-2010) surface water and ground water monitoring data from our Orchid Meadows field site (Fig. 2) near Clear Lake, South Dakota (Johnson et al. 2004). WLS successfully modeled the key hydrological properties of 10 prairie wetlands including spring rise, summer drawdown, hydroperiod, depth to ground water, and water-level oscillations during wet-dry cycles (Johnson et al. 2010). The climate of the Orchid Meadows site is close to the mean for the entire PPR. The ability of WLS to accurately simulate the extremes of weather at our monitoring site gave us confidence that simulations at stations farther west (drier) and farther east (wetter), where no long-term monitoring data were available, were modeled satisfactorily as well. 


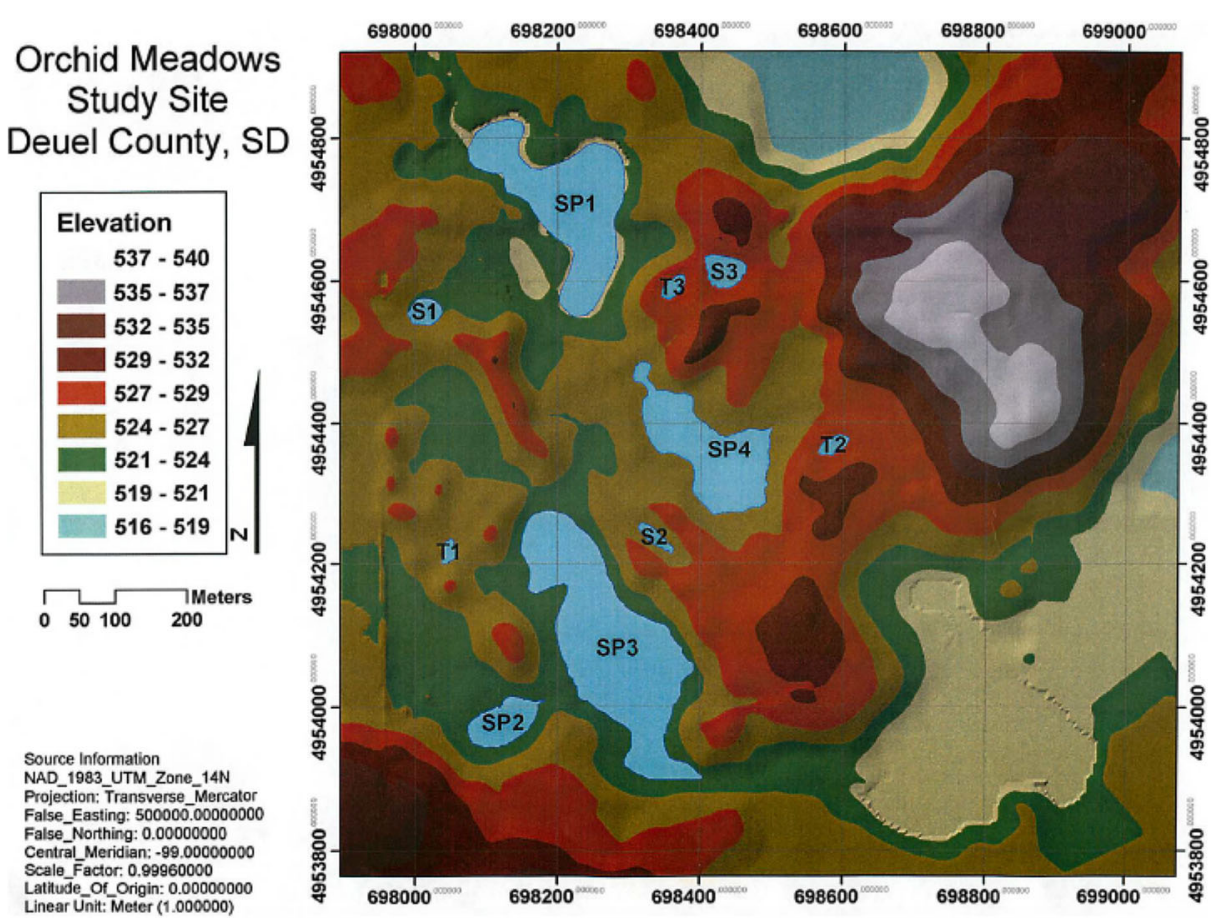

Fig. 2 The hydrologic setting of the prairie wetland complex at the Orchid Meadows field site near Clear Lake, South Dakota. Wetland permanence classes are: $\mathrm{SP}=$ semi-permanent; $\mathrm{S}=$ seasonal; $\mathrm{T}=$ temporary

The Cover Cycle Index (CCI) in WLS served as the primary metric of wetland functional dynamics and was based on two variables given equal weight: the proportion of time model wetlands spent in the hemi-marsh stage during the simulation period, and the average number of cover cycle state changes (i.e., switches) between cover cycle classes over the same time period (Johnson et al. 2010). Johnson et al. (2010) proposed the CCI as a proxy for the productivity and functionality of the wetland complex, not just for semi-permanent wetlands.

To determine the amount of switching and the proportion of time during a simulation that model wetlands spent in each of the three cover-cycle stages (dry marsh, lake marsh, hemimarsh), it was necessary to know the stage at every model time step. Switching between stages (Supplemental Table 1) was prescribed using a Markov-type transition probability model based on water depth and duration rules adapted from Poiani and Johnson (1993) and used in Johnson et al. (2010).

Each of the two components of CCI was scaled to a value between 0 and 1.3 and then averaged. The resulting index approached 1.3 when a simulated wetland complex underwent many switches among cover cycle classes and had a high proportion of time steps in the hemimarsh stage. The index approached 0 when a wetland complex had few switches and proportionally few to no time steps spent in the hemi-marsh stage.

\subsection{Weather data sets (stations)}

Data from 19 weather stations (Fig. 1), each with 100 years of data (1906-2005), were used in WLS to simulate spatial patterns of wetland conditions across the PPR. Three widely-separated 
stations from each of six PPR ecoregions were selected based on their length and completeness of record. Missing weather data (daily air temperature and precipitation) were reconstructed (Millett et al. 2009) by averaging two or three neighboring stations, usually within $40 \mathrm{~km}$. For the few stations where only one nearby station was available, the single best estimator method was used (Eischeid et al. 2000). This was the same data set compiled and analyzed by Millett et al. (2009) except that we added years 2001-2005.

Mean daily air temperature averaged across the 19 stations increased by approximately $1{ }^{\circ} \mathrm{C}$ during the 20th century, slightly above the global average of $0.6{ }^{\circ} \mathrm{C}$ (Millett et al. 2009). Thus, this data set contains an internal warming trend. Any temperature increases applied to this data set would be on top of that historic base increase.

\subsection{Model simulations}

Threshold experiments using climate data from the 19 weather stations for the 100 -year historic period were conducted using 3 of the 4 semi-permanent wetlands (SP1, 3, 4; Fig. 2) present in our wetland complex. Only simulations of the semi-permanent wetlands were analyzed because they fit the classic wetland cover cycle concept (van der Valk and Davis 1978). Wetland SP2 was excluded because it was borderline hydrologically between semipermanent and seasonal permanence types. These 3 wetlands differed in basin morphometry and in topographic setting and therefore exhibited variation in hydroperiod and in other wetland parameters.

We used the delta method (Giorgi and Mearns 1991) to examine the CCI responses of modeled wetlands to a warming climate. This method adds coarse scale climate predictions to historical data sets of high-resolution observations, such as ours described above. For our experiments, the mean daily temperature record at each weather station was converted into 26 modified 100-yr. data sets, one for each one-fifth degree Celsius temperature increment up to $5.0^{\circ} \mathrm{C}\left(0^{\circ},+0.2^{\circ},+0.4^{\circ}, \ldots,+4.8^{\circ},+5.0^{\circ} \mathrm{C}\right)$. The increment was uniformly applied across all mean daily temperatures in the data set. Temperature adjustments were fixed at the start of simulations and were not made during model runs to simulate incremental warming over time. Simulated CCI values for each station/temperature increment were averaged for the 3 semipermanent wetlands. Precipitation records were not adjusted, but have been in previous studies (Johnson et al. 2005, 2010). This method assumes no changes in temperature variability in the future because variability is fixed within the historic climate regime.

In addition to the calculation of CCI scores, the cover cycle status was coded for each wetland by year, weather station, and temperature increment: 1 for lake; 2 for hemi-marsh; or 3 for dry, and then summed for the 3 wetlands. For graphical purposes, each summed value was assigned a color shade [dark blue for a value of 3 (all wetlands lake marsh), green for a value of 6 (predominantly hemi-marsh) and tan for a value of 9 (all wetlands dry marsh)]. Values in between these received intermediate color shades. This enabled the creation of a graphical mosaic showing broad patterns of cover cycle changes associated with warming over the 100year simulation period.

\section{Results}

An example of the relationship among CCI, cover stage dynamics, and temperature is shown for the Morris, $\mathrm{MN}$ weather station (Fig. 3). Under historic conditions $\left(0{ }^{\circ} \mathrm{C}\right.$ weather data set 


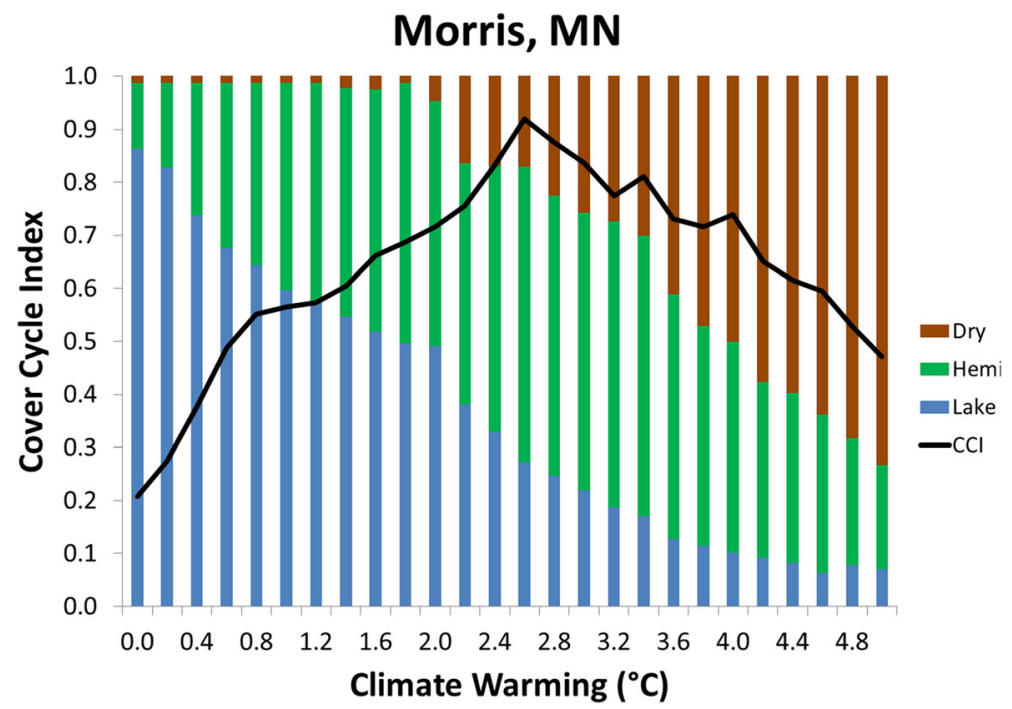

Fig. 3 Simulated response of the CCI and cover cycle stages to increasing temperature for the Morris, Minnesota weather station using the WLS model

w/o adjustment) CCI was quite low (0.20) because the model wetlands were very wet; the lake marsh stage dominated almost $90 \%$ of the time. CCI increased sharply as warmer temperature weather data sets were used, and the proportions of dry and hemi-marsh stages increased. The weather data set with the historic temperatures raised by $2.6^{\circ} \mathrm{C}$ produced the highest CCI score of 0.92. The cover stage ratios at peak CCI were approximately 17:56:27 for dry, hemi-, and lake marsh stages, respectively. Experiments using warmer weather data sets increased the proportion of time spent in the dry marsh stage and substantially decreased time spent in both hemi- and lake marsh stages. This weather station was unique in that it spanned the nearly complete cover ratio range over the $5{ }^{\circ} \mathrm{C}$ temperature range.

\subsection{Rapid changes and reversals}

Two types of non-linear effects were evident from the model experiments. First, trajectories of CCI response curves to temperature increases were highly variable among stations, but most fit well into classes as either increasing, decreasing, or peaked (trajectory reversal) (Fig. 4). Second, small to modest changes in CCI occurred at most stations as air temperature was increased. These shifts were sporadic and generally small enough not to change the overall trajectory of the response curves of CCI to changing temperature; however, some sharp increases changed CCI by 10-20\%. For example, a break-point in the $\mathrm{CCI}$ curve for Morris, $\mathrm{MN}$ occurred at $0.8{ }^{\circ} \mathrm{C}$; similar break-points occurred in the curve for Algona, IA between warming of $4-5{ }^{\circ} \mathrm{C}$ (Fig. 4). Thus, from our model experiments, we distinguished between smaller, episodic shifts and larger, response curve trajectory reversals as threshold responses to warming.

Nearly half of the stations exhibited CCI curves that peaked and then reversed course as temperature increased (Fig. 4a). Another third exhibited steadily declining curves (Fig. 4b), while only two stations exhibited steadily increasing CCI scores (Fig. 4c). Lastly, three stations (Medicine Hat, Poplar, Saskatoon not shown) were unresponsive to increasing temperature. 

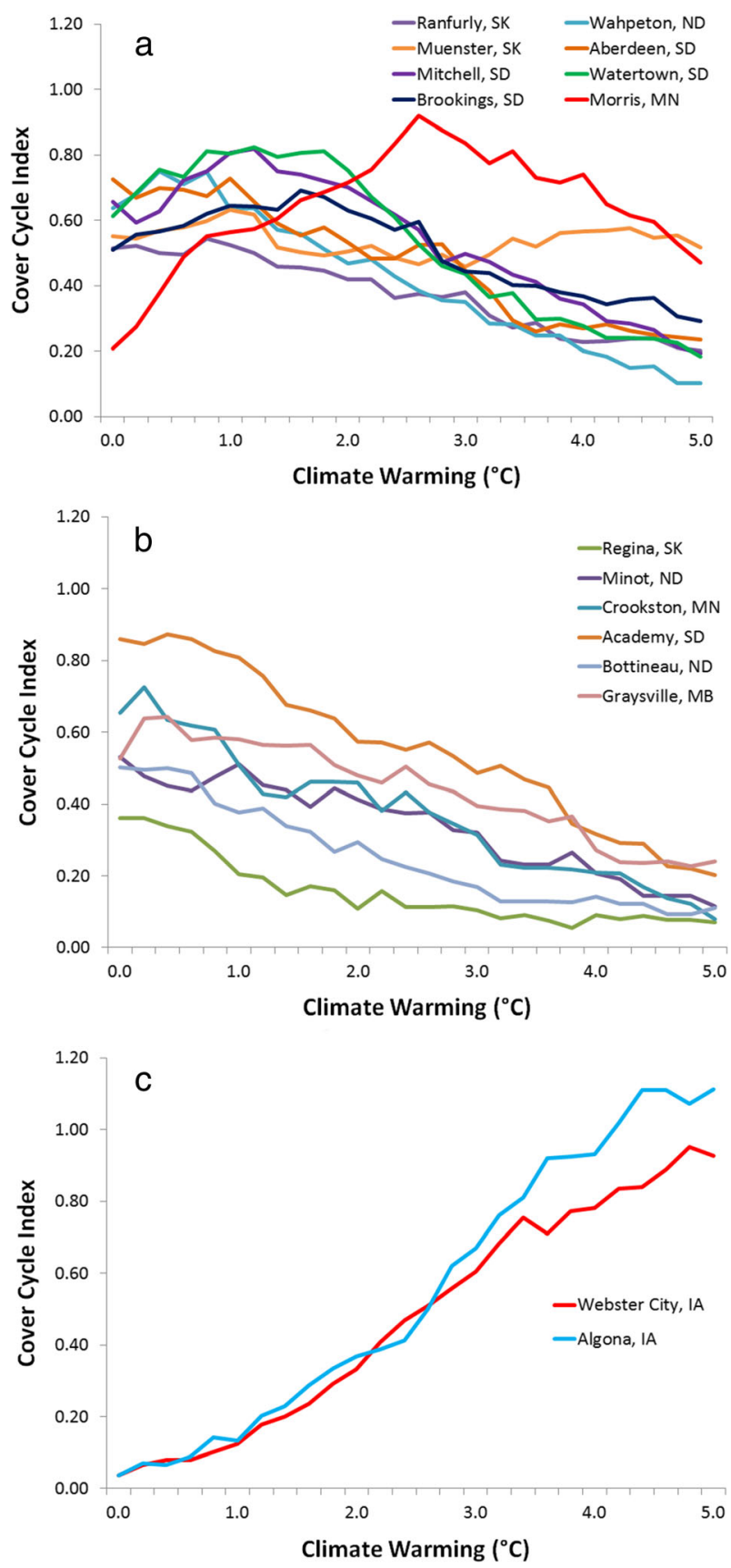

Fig. 4 Divergent simulated CCI responses to climate warming at 16 PPR weather stations: a peaking; b decreasing; c increasing. Unresponsive stations not shown (Saskatoon, Medicine Hat, Poplar)

The response patterns corresponded closely to the strong northwest-southeast climate gradient across the PPR (Millett et al. 2009). Stations located in the more central portion of the PPR (e.g., Watertown, Morris) initially responded positively to increasing temperature but 
eventually peaked and then decreased steadily (Fig. 4a). Most of these stations with trajectory reversal registered moderate to high CCI scores at the start of the simulation (historic climate), indicating that during the 20th century they were quite productive. All stations ended the simulation with much lower CCI scores than those with which they started.

Stations from the west-central portion of the PPR (Academy, Regina) exhibited consistently declining CCI scores as temperature increased. These stations also started the simulation with moderate to high CCI scores; the scores on average dropped approximately $25 \%$ per degree of warming (Fig. 4b). For example, the Academy, SD, weather station had the highest CCI score in the PPR during the 20th century; it dropped steeply from 0.85 to 0.20 over the $5{ }^{\circ} \mathrm{C}$ range.

Two stations in the extreme southeastern PPR showed consistently increasing CCI scores during the temperature simulation. These stations began the simulation with extremely low CCI scores because wetlands were too wet to go through all cover cycle stages (Fig. 4c). As model temperatures were raised, CCI rose as well, until reaching maximum values near 1 at $5{ }^{\circ} \mathrm{C}$.

At the opposite extreme, the three driest stations in the northwest (Medicine Hat, Poplar, Saskatoon) were unresponsive because of insufficient water depth and duration to reach the wetter cover cycle stages. CCI scores were extremely low before temperature was increased. Increasing temperature for these stations only lowered the already dim prospects of reaching the lake marsh stage.

\subsection{Distribution of peaks in climate space}

Plotting the temperature increment at which the peak CCI value occurred from each response curve clearly revealed what the functional prospects would be for each weather station or sub-region of the PPR in a warmer atmosphere (Fig. 5). Peak CCI values from most of the drier, western stations occurred on or near the graph ordinate; wetlands near these stations would not improve from any significant warming. The productivity of some centrally located stations would improve with $1-1.5{ }^{\circ} \mathrm{C}$ of warming because their peak CCI occurred under temperatures slightly warmer than those of the 20th century. Few station peaks lay beyond the $1.5-2{ }^{\circ} \mathrm{C}$ increment. These are the wettest eastern stations that registered low CCI scores under the current climate, but are projected to reach the formerly rarely attained dry marsh stage if the PPR experiences much warmer temperatures in the future $\left(3-5^{\circ} \mathrm{C}\right)$. The three unresponsive western stations occur at the bottom of the graph with extremely low CCI scores.

CCI averaged for the 19 weather stations rose slightly with temperature increases up to $1.0{ }^{\circ} \mathrm{C}$ but then steadily decreased by about $40 \%$ across the $0-5{ }^{\circ} \mathrm{C}$ gradient (Fig. 6). A second analysis removed the 3 unresponsive western stations (Poplar, Saskatoon, Medicine Hat) and 4 stations located near the eastern PPR border (Webster City, Algona, Morris, Crookston) from the set of PPR weather stations. The latter stations occurred in areas where wetland drainage has left few functional basins (Tiner 2003) and virtually no grassland habitat. Including only stations from the PPR subregion that were most responsive to model temperature increases, had more functional wetlands and grassland habitat, and contributed the most to PPR productivity during the last century, better represents the impact of warming on overall PPR wetland productivity. The CCI curve generated from this analysis (Fig. 6) started higher (0.60), increased similarly to the all station curve, but then dropped more 


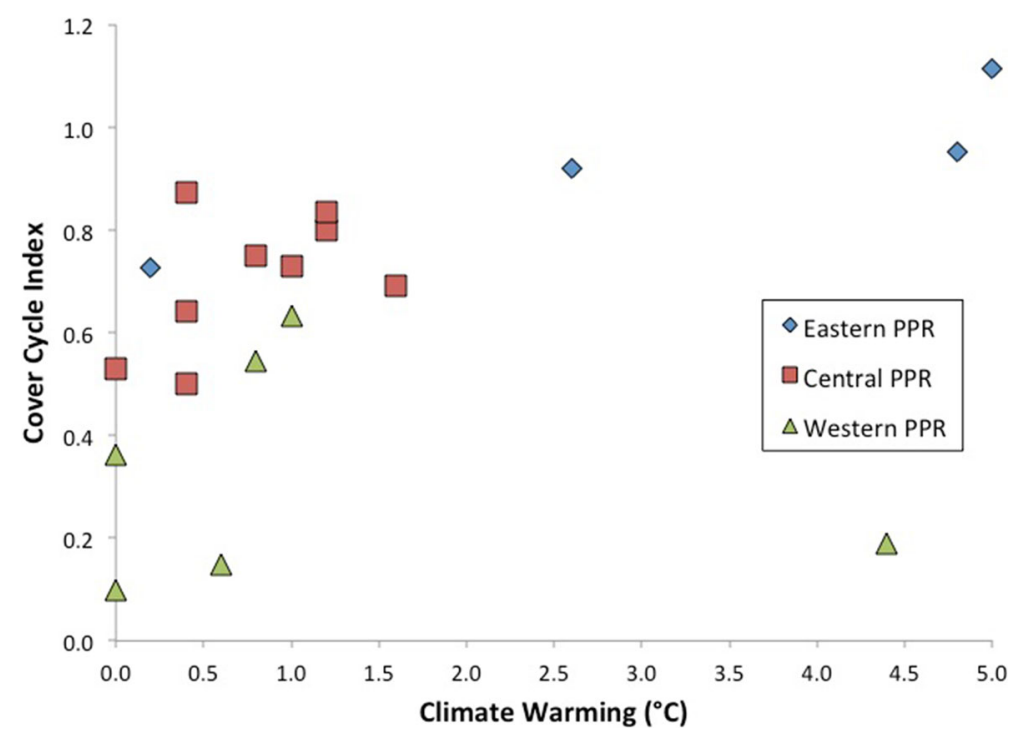

Fig. 5 Position of peak CCI in climate space for each of 19 weather stations and their sub-regions under incremental warming from 0 to $5{ }^{\circ} \mathrm{C}$ using the WLS model

steeply and ended with a lower CCI score (0.20). CCI dropped overall by approximately $70 \%$.

The spatial/temporal patterns of CCI response to warming differed markedly across an east to west gradient of weather stations (Fig. 7). The most dynamic conditions at each of the 3 weather stations occurred at different degrees of warming. For example, the wettest station (Algona, IA) exhibited the greatest heterogeneity of cover cycle stages at $5{ }^{\circ} \mathrm{C}$, the warmest temperature increment (Fig. 7); the Morris, $\mathrm{MN}$ station with moderate precipitation showed the greatest heterogeneity at $2-3{ }^{\circ} \mathrm{C}$ warming, while Academy, $\mathrm{SD}$, the driest of the 3 stations, was the most dynamic station under the historic $\left(0{ }^{\circ} \mathrm{C}\right.$ increment $)$ climate. Uniform blocks of color within the mosaic graphs (Fig. 7) indicate a climate that causes wetlands to become stuck in either wet (blue) or dry (tan) phases of the cover cycle, unable to either dry out or to flood

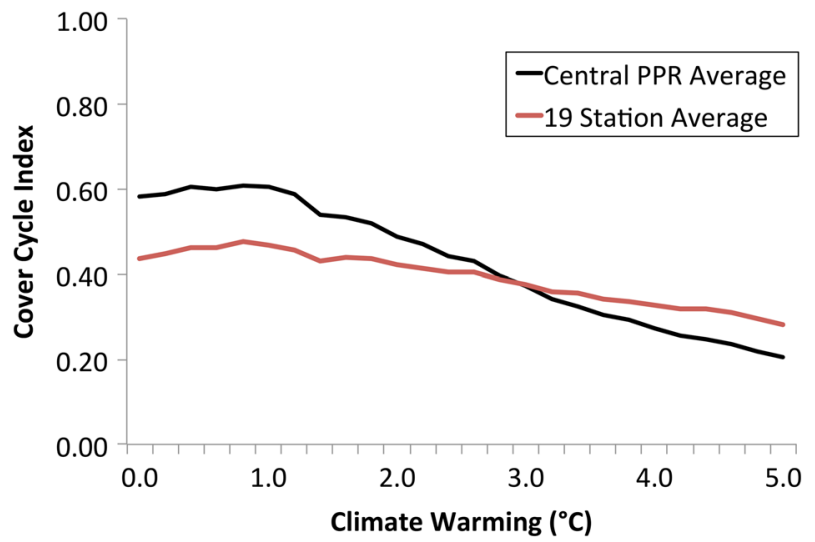

Fig. 6 Average response of CCI at all weather stations and of centrally-located stations in the PPR under incremental climate warming from 0 to $5{ }^{\circ} \mathrm{C}$ 


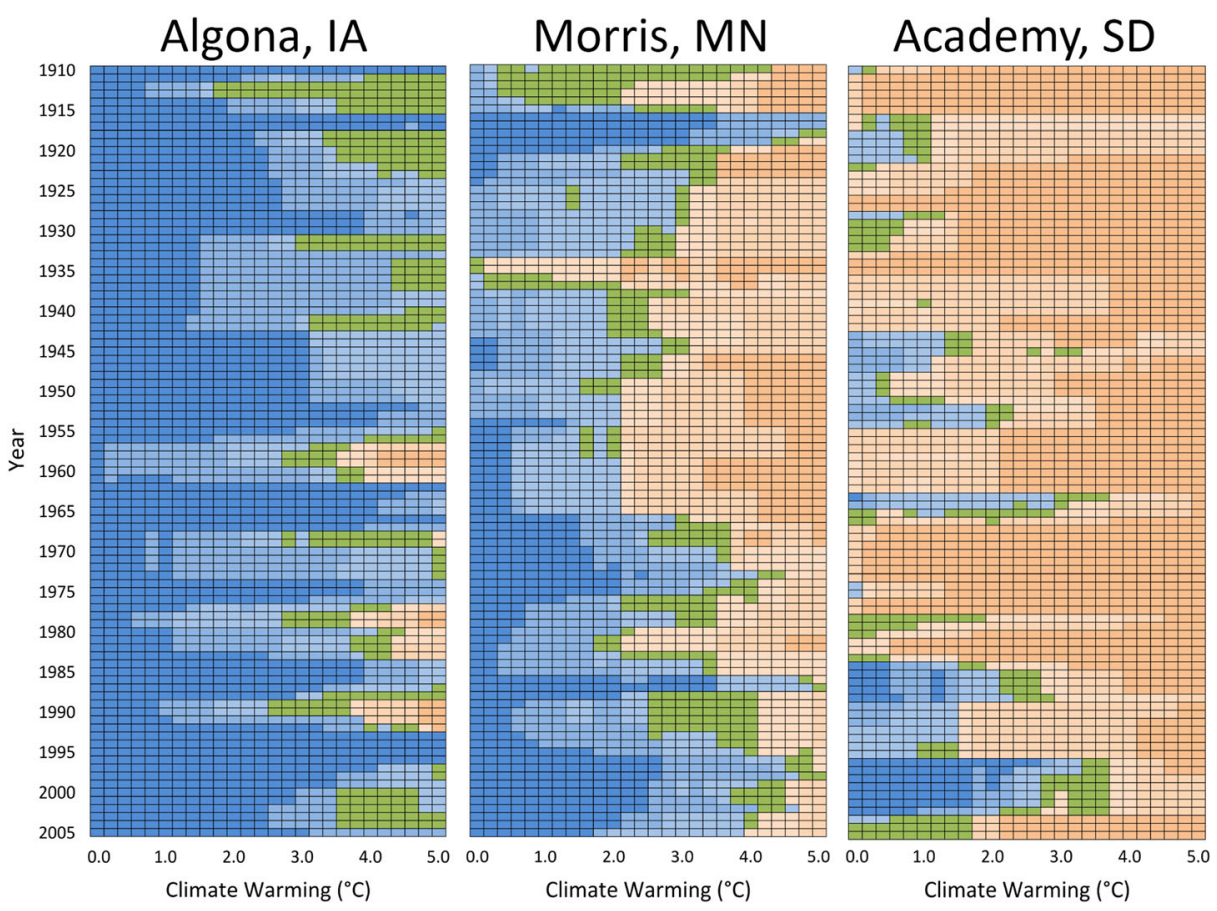

Fig. 7 Mosaic patterns of the simulated response of wetlands at three weather stations (east, central, west: left to right) to climate warming $\left(0-5^{\circ} \mathrm{C}\right)$ over the 100 -year climate data set. The cover cycle stage of each matrix cell is color-coded (blue tones = lake marsh; green tones = hemi-marsh; brown tones = dry marsh). CCI peaks at the highest temperature range at Algona, moderate temperature range at Morris, and lowest temperature range at Academy

wetlands at depths and duration that trigger changes in emergent vegetation and initiate cycling.

\section{Discussion}

Two types of thresholds were evident from model experiments: trajectory reversals and rapid shifts in CCI scores. If reversals occurred, they occurred only once per weather station during warming experiments; most often they occurred when the CCI initially responded positively to increasing temperature but later turned negative. These "turning points" were important indicators of specific temperature thresholds at which wetlands at a given station become chronically less dynamic and lose out to further climate warming.

Temperature affects wetland water levels in multiple ways in WLS, but the major processes that affect the probability of surpassing depth/duration thresholds and enabling switching to occur between cover stages were: evapotranspiration rates, the length of the ice free season, and the sublimation rate of the snow pack that affects spring runoff. The largest increases in CCI occurred when the number of switches and the proportion of the model wetlands in hemimarsh conditions increased simultaneously. Smaller increases usually occurred when one or the other increased. Break-points were associated with counterbalancing values that flattened out CCI curves followed by a resumption of increases in both CCI components. 
The largest impact of increasing temperature may come when historically productive areas of wetlands become chronically unproductive because of lower cycling rates and longer residence in the dry marsh phase. Some subregions of the PPR may experience improved productivity by modest drying at the start of significant climate warming, but then may experience a trajectory reversal and become chronically less productive. Our analysis indicates that these changes can become noticeable with only a few tenths of a degree increase in temperature, if the warming occurs when the system is approaching a cycling threshold. Previous results suggest that recent climate warming and drying (1975-2005) already may have reduced wetland productivity in the western Canadian prairies (Werner et al. 2013). These results are consistent with the global pattern of temperatures rising more at higher than at lower latitudes (IPCC 2007).

It is important to note that our simulated temperature increases were produced on top of recorded warming of about $1{ }^{\circ} \mathrm{C}$ in the PPR during the 20th century. Hence, a $2{ }^{\circ} \mathrm{C}$ model increase in temperature above the present climate baseline, plus actual warming of $1{ }^{\circ} \mathrm{C}$, would be approximately $3{ }^{\circ} \mathrm{C}$ above a pre-industrial baseline. Working forward from the present climate baseline (yr. 2005), we found that the warmer climate scenarios altered the dynamics of the wetland cover cycle at nearly all weather stations. Stations responded individualistically to warming, but geographic patterns were evident. Most stations would improve slightly from a warming of approximately $1.5^{\circ} \mathrm{C}$ or less. Only the wetter eastern stations and one central station exhibited higher CCI scores with temperature increases beyond $1.5{ }^{\circ} \mathrm{C}$. The eastern stations that could become more productive represent sub-regions where most wetlands were drained and grassland was converted to cropland many decades ago. A more favorable wetland climate in this sub-region could only be beneficial if wetlands were present or if they were restored in the future.

Overall, the present baseline analysis showed that nearly all PPR stations would lose functionality if a temperature threshold of $1.5^{\circ}-2^{\circ} \mathrm{C}\left(2.5^{\circ} \mathrm{C}-3.0^{\circ} \mathrm{C}\right.$ pre-industrial baseline $)$ were to be exceeded. Climate projections for the U. S. portion of the PPR meet or exceed these thresholds. For example, Steen et al. (2014) forecasted for 2040-2049 a $2.9{ }^{\circ} \mathrm{C}$ increase in mean temperature relative to the 1981-2000 baseline using a statistically downscaled approach (CGCM; Canadian Center for Climate Modeling and Analysis, Third Generation Coupled Global Climate Model 3.1) and a $3.8^{\circ} \mathrm{C}$ temperature increase using a dynamically downscaled approach (WRFc; Weather Research and Forecasting Model), both based on the mid-high IPCC emission scenario. These results are consistent with those of the Coupled Model Intercomparison Project Phase 5 (CMIP5) ensemble model experiments using the Representative Concentration Pathways - RCP2.6 and RCP8.5 used by the IPCC 5th Assessment report (Romero-Lankao et al. 2014).

Other studies have identified a temperature threshold, similar to ours, beyond which the functionality of natural and human ecosystems would degrade rapidly. For example, Hansen et al. (2013) concluded that "a cumulative emission of approximately 1000 gigatons of carbon, sometimes associated with $2{ }^{\circ} \mathrm{C}$ global warming (pre-industrial baseline), would spur "slow" feedbacks and eventual warming of $3^{\circ}-4{ }^{\circ} \mathrm{C}$ with disastrous consequences." Rockstrom et al. (2009 a,b) reported a growing convergence among scientists towards a $2{ }^{\circ} \mathrm{C}$ "guardrail" limit above pre-industrial levels. Victor and Kennel (2014), however, reject a common societal goal to stop global warming at $2{ }^{\circ} \mathrm{C}$ above pre-industrial levels. Rather, they argue that new goals should be adopted that track planetary vital signs, such as changes in the ocean heat content, that are better understood as a drivers of climate. 
Drainage and land use change have shrunk the effective geographic area of the PPR and reduced functional wetland densities (Wright \& Wimberly 2013; Johnston 2013). Wetland and grassland losses have been greatest in the wettest (easternmost) portion of the PPR where agricultural productivity and land values are the highest. Climate change may further shrink the effective PPR, but this time in the west by increasing the proportion of years that conditions will be too dry to produce functional wetlands.

Climate is the primary driver of prairie wetland dynamics; however, many other factors, such as farming practices, wetland drainage, government and NGO easement programs, and game harvesting are important factors that affect wildlife populations and wetland productivity, persistence, and function. Considerable work still is needed to provide managers with a comprehensive analysis of the likely future of wetlands in the PPR. In particular, more refinement of climate scenarios is needed, such as the use of downscaled climate projections from regional and global climate models (e.g., Tabor and Williams 2010, McIntyre et al. 2014).

\section{Conclusions}

1. The vegetation cover cycle of prairie wetlands that controls their functional dynamics is highly sensitive to climate warming. The completeness and speed of this cycle, as measured by a cover cycle index (CCI), depends on sufficient climate heterogeneity (drought and deluge) to exceed thresholds influenced by temperature. The climate must be sufficiently dry to switch into the dry marsh stage and sufficiently wet to switch into the lake marsh stage.

2. Temperature increases cause two types of threshold responses in the CCI: rapid changes and trajectory reversals. The frequency of the former was caused by the amount of back and forth switching, while reversals indicated a permanent switch from increasing to decreasing productivity as temperature increased.

3. Increasing temperature reduced the frequency of switches and lowered the chance of complete cycling. Wetlands in nearly all sub-regions of the PPR would lose function beyond climate warming of about $1.5^{\circ}-2.0^{\circ} \mathrm{C}$ above present baseline temperature, a threshold identified in other climate change studies.

Acknowledgments Research for this manuscript was funded by the US Environmental Protection Agency (EPA), Science To Achieve Results (STAR) program, managed by the EPA's Office of Research and Development, National Center for Environmental Research, and the US Geological Survey Climate and Land Use Change Research and Development Program. We thank the WETLANDSCAPE development team for collaboration throughout the project, including Karen Poiani, Richard Voldseth, Bruce Millett, Tagir Gilmanov, David Naugle, John Tracy, and Rosemary Carroll. Any use of trade, product, or firm names is for descriptive purposes only and does not imply endorsement by the U.S. Government.

\section{References}

Batzer DP, Sharitz RR (2006) Ecology of freshwater and estuarine wetlands. University of California Press, p. 568

Burkett V et al. (2005) Nonlinear dynamics in ecosystem response to climatic change: case studies and policy implications. Ecological Complexity 2:357-394

Clair TA (1998) Canadian freshwater wetlands and climate change. Clim Chang 40:163-165 
Eischeid JK, Pasteris PA, Diaz LH, Plantico MS, Lott NJ (2000) Creating a serially complete, national daily time series of temperature and precipitation for the western United States. J Appl Meteorol 39(9):1580-1591. doi: 10.1175/1520-0450(2000)039<1580:CASCND>2.0.CO:2

Fagre DB et al. (2009) Thresholds of climate change in ecosystems. A report by the U. S. Climate Science Program and the Subcommittee on Global Change Research. U.S. Geological Survey, Reston

Gardner RH et al. (1987) Neutral models for the analysis of broad-scale landscape pattern. Landscape Ecology 1: 19-28

Giorgi F, Mearns LO (1991) Approaches to regional climate change simulation: Rev. of Geophys. 29:191-216

Groffman PM et al. 2006. Ecological thresholds: the key to successful environmental management or an important concept with no practical application? Ecosystems 9:1-13

Gunderson LH (2000) Ecological resilience-theory to practice. Annu Rev Ecol Syst 31:421-439

Gunderson LH, Holling CS (eds) (2002) Panarchy: understanding transformations in human and natural systems. Island Press, Washington, DC

Guntenspergen GR and Gross J. 2014. Threshold concepts: implications for the management of natural resources. Pp. 1-7, In: Guntenspergen GR (ed). Application of threshold concepts in natural resource decision making. doi:10.1007/978-1-4899-8041-0_1. Springer Science + Business Media Publ.

Hansen J, Kharecha P, Sato M, Masson-Delmonte V, Ackerman F, Beerling DJ, Hearty PJ, Hoegh-Guldberg O, Hsu S-L, Parmesan C, Rockstrom J, Rohling EJ, Sachs J, Smith P, Steffen K, Van Susteren L, von Schuckmann K, Zachos JC (2013) Assessing "dangerous climate change": required reduction of carbon emissions to protect young people, future generations, and nature. PLOS ONE 8(12):e81648

Holling CS (1973) Resilience and stability of ecological systems. Annu Rev Eco Syst 4:1-23

Intergovernmental Panel on Climate Change (IPCC). Climate Change 2007. Cambridge University Press, New York. 996 pp.

Johnson WC (1998) Adjustment of riparian vegetation to river regulation in the Great Plains, USA. Wetlands 18 : 608-618

Johnson WC et al. (2010) Prairie wetland complexes as landscape functional units in a changing climate. BioScience 60:128-140

Johnson WC et al. (2004) Influence of weather extremes on the water levels of glaciated prairie wetlands. Wetlands 24:385-398

Johnson WC et al. (2005) Vulnerability of northern prairie wetlands to climate change. BioScience 55:863-872

Johnston CA (2013) Wetland losses due to row crop expansion in the Dakota Prairie Pothole Region. Wetlands $33: 175-182$

Larson D (1995) Effects of climate on numbers of northern prairie wetlands. Clim Chang 30:169-180

May RM (1977) Thresholds and breakpoints in ecosystems with a multiplicity of stable states. Nature 269:471477

McIntyre N et al. (2014) Climate forcing of wetland landscape connectivity in the Great Plains . Front Ecol Environ 12(1):59-64

Millett B, Johnson WC, Guntenspergen GR (2009) Climate trends of the North American prairie pothole region 1906-2000. Clim Chang 93:243-267

Mitsch WJ, Gosselink JG (2007) Wetlands, 4th edn. Wiley

Murkin H, van der Valk AG, Clark WR (2000) Prairie Wetland Ecology: The Contribution of the Marsh Ecology Research Program. Iowa State University Press.

Poiani KP, Johnson WC (1993) A spatial simulation model of hydrology and vegetation dynamics in semipermanent prairie wetlands. Ecological Applications 3:279-293

Poiani KP, Johnson WC, Kittel T (1995) Sensitivity of a prairie wetland to increased temperature and seasonal precipitation changes. Water Resources Bulletin 31:283-294

Rockstrom J et al. (2009a) Planetary boundaries: exploring the safe operating space for humanity. Ecology and Society $14: 32$

Rockstrom J et al. (2009b) A safe operating space for humanity. Nature 461:472-475

Romero-Lankao P, Smith JB, Davidson DJ, Diffenbaugh NS, Kinney PL, Kirshen P, Kovacs P, Villers Ruiz L (2014) North America. In: Barros VR, Field CB, Dokken DJ, Mastrandrea MD, Mach KJ, Bilir TE, Chatterjee M, Ebi KL, Estrada YO, Genova RC, Girma B, Kissel ES, Levy AN, MacCracken S, Mastrandrea PR, White LL (eds) Climate Change 2014: Impacts, Adaptation, and Vulnerability. Part B: Regional Aspects. Contribution of Working Group II to the Fifth Assessment Report of the Intergovernmental Panel on Climate Change. Cambridge University Press, Cambridge, pp. 1439-1498

Scott ML, Friedman JM, Auble GT (1996) Fluvial process and the establishment of bottomland trees. Geomorphology 14:327-339

Steen V, Skagen SK, Noon BR (2014) Vulnerability of breeding waterbirds to climate change in the Prairie Pothole Region, U.S.A. PLOS ONE 9(6):e96747 
Tabor K, Williams JW (2010) Globally downscaled climate projections for assessing the conservation impacts of climate change. Ecol Appl 20(2):554-565

Tiner RW (2003) Geographically isolated wetlands of the United States. Wetlands 23(3):494-516

van der Valk AG (ed) (1989) Northern prairie wetlands. Iowa State University Press, Ames, p. 400

van der Valk AG (2005) Water-level fluctuations in North American prairie wetlands. Hydrobiologia 539:171188

van der Valk AG (2012) The biology of freshwater wetlands, 2nd edn. Oxford University Press, New York, p. 280

van der Valk AG, Davis CB (1978) The role of seed banks in the vegetation dynamics of prairie glacial marshes. Ecology 59:322-335

Victor DG, Kennel CF (2014) Ditch the $2{ }^{\circ} \mathrm{C}$ warming goal. Nature 514:30-31

Weller MW, Fredrickson LM (1974) Avian ecology of a managed glacial marsh. Living Bird 12:269-291

Weller MW, Spatcher CE (1965) Role of habitat in the distribution and abundance of marsh birds. Iowa State University Agricultural and Home Economics Experimental Station. Special Report no. 43.

Werner B, Johnson WC, Guntenspergen GR (2013) Evidence for 20th century warming and wetland drying in the North American Prairie Pothole Region. Ecology and Evolution. Wiley Online Library. doi:10.1002/ ece 3.71

Winter TC (2000) The vulnerability of wetlands to climate change: a hydrologic landscape perspective. Journal of the American Water Resources Association 36:305-311

Winter TC, Rosenberry DO (1998) Hydrology of prairie pothole wetlands during drought and deluge: a 17-year study of the Cottonwood Lake wetland complex in North Dakota in the perspective of longer term measured and proxy hydrologic records. Clim Chang 40:180-209

Winter TC, Woo MK (1990) Hydrology of lakes and wetlands. Pages 159-187 In: Wolman MG, Riggs HC (eds) Surface Water Hydrology: The Geology of North America, vol. 1. Geological Society of America.

Wright CK, Wimberly MC (2013) Recent land use change in the western corn belt threatens grasslands and wetlands. Proceedings of the National Academy of Science USA 110(10):4134-4139 


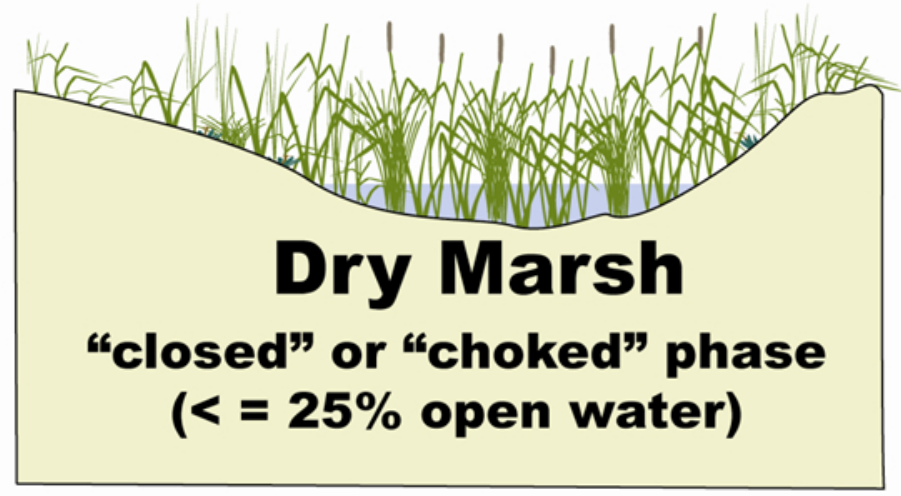

Normal Rainfall

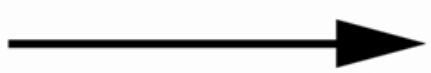

Muskrat Damage

Lake Marsh "open water" phase ( $>=75 \%$ open water)

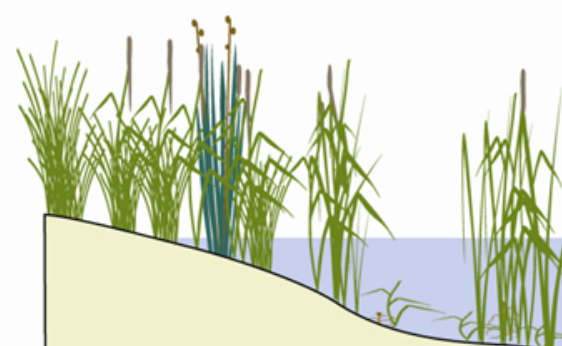

Regenerating Marsh "hemi-marsh" phase (26\% - $74 \%$ open water)

Senescence Disease Insects High Water

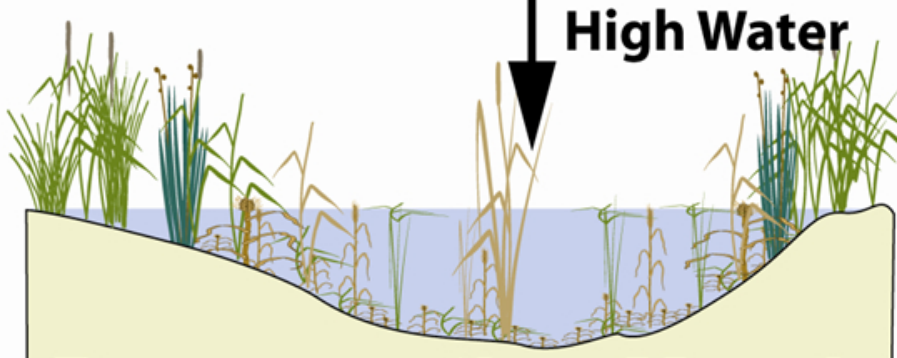

Degenerating Marsh

"hemi-marsh" phase (26\% - $74 \%$ open water) 


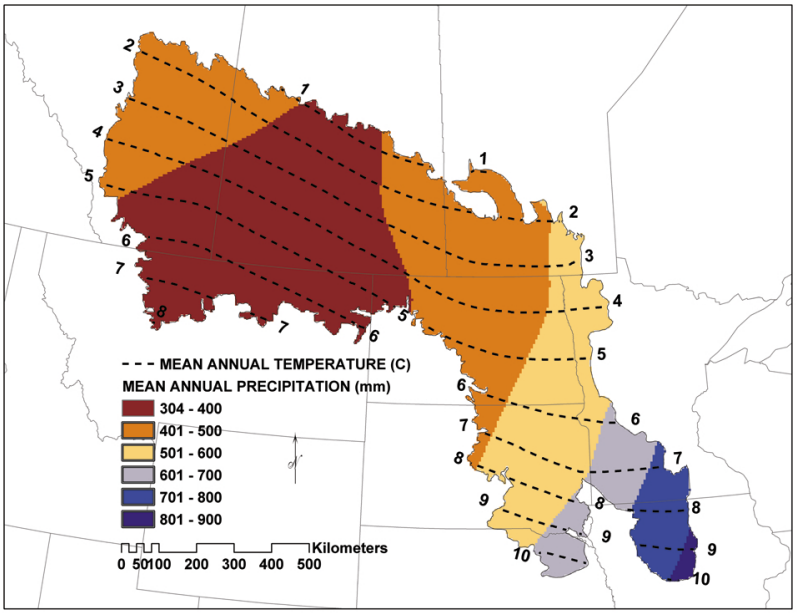


Supplemental Table 1. Water depth and duration rules for cover cycle stage switches. From Johnson et al. (2010), modified from Poiani and Johnson (1993).

\begin{tabular}{|c|c|c|c|}
\hline Current Stage & New Stage & Maximum Depth (meters) & Duration \\
\hline Lake marsh & Hemi-marsh & $<0.5 \mathrm{~m}$ & May-July \\
\hline Hemi-marsh & Lake marsh & $>0.75 \mathrm{~m}$ & 2 years \\
\hline Hemi-marsh & Dry marsh & $<0.1 \mathrm{~m}$ & May-July \\
\hline Dry marsh & Hemi-marsh & Between 0.4 and 1.0 & 1.5 years \\
\hline Dry marsh & Lake marsh & $>0.75 \mathrm{~m}$ & 2 years \\
\hline
\end{tabular}

